\title{
Research and Practice on the Discipline Competition based Education Mode for College Students under the Internet Plus Background
}

\author{
Xinxin Xie ${ }^{1, a}$, Wenzhun Huang ${ }^{1, b^{*}}$ and Hui Zhang ${ }^{1, c}$ \\ 1Department of Electronic Information Engineering, Xijing University, Xi'an 710123, China \\ a346148500@qq.com, bhuangwenzhun@xijing.edu.cn, czhang_hui@xijing.edu.cn
}

Keywords: Internet Plus; Discipline Competition; Education Mode; College Students; Practice.

\begin{abstract}
In this paper, we conduct review and research on the current discipline competition based education mode for college students under the Internet plus background. Since the popularization of higher education entered the stage, a lot of undergraduate course colleges and universities to establish the talents cultivation orientation, began to focus on training in design, development, management, which has strong practical ability and the innovative applied talents. Positioning requirement changes, cultivation of talents training mode should also change, to guide students to establish the innovation idea, cultivate the ability to practice as the fundamental purpose of the competition of science and the technology, in process of applied talent training plays more and more important role. With high-end discipline competition is a platform of talent to stand out, so to participate in competition of science and technology is more excellent academic performance, innovative outstanding students, to guide the level of the teachers have high requirements, competition teachers not only has the strong ability of scientific research that should also have rich practical experience.
\end{abstract}

\section{Introduction}

In the 21 st century is the era of knowledge economy, in order to adapt the knowledge economy to the knowledge talented person's demand, many countries have put education especially science education with the priority development of the importance. Higher education is the education of "dragon" as it determines the quantity and quality of high-level personnel training, to a great extent, decides the national competition in the success or failure in the future [1-2].

According to the literature review, as there are lots of challenges existed for the current education mode such as the listed aspects. (1) Unreasonable setting of curriculum system. Emphasis on basic courses and general courses education, basic classes and the class of general education courses to take up more, real professional class hours less, less practice training, lack of elasticity as causes students innovation ability and comprehensive ability is not enough. On the general curriculum, the lack of forward-looking in curriculum design, standardization and system cohesion, content of courses have overlapping phenomenon and the little amount of information in class. (2) Boring and monotonous traditional experimental teaching, students can begin, but does not pay attention to the experimental principle and process of mutual cooperation ability is not strong, as the practice innovation ability is limited. (3) Engineering courses teaching methods lack of characteristics. In classroom teaching, most teachers still give priority to in order to teach, and the students passively accept knowledge, students' thinking in knowledge is less, the enthusiasm of the students lack of practical operation and ability, lack of opportunities in the enterprise practice, the contradiction in teaching lags behind that of the enterprises need. In a new way of teaching, teachers should pay attention to operation combination of theory and practice of computer through teaching that can put the knowledge into the action faster.

The biggest advantage of classroom teaching is the ability to the system comprehensive knowledge, but it is often more difficult to mobilize students' initiative. The competition the biggest advantage is that can enhance students' competitive consciousness, practice of classroom learning to knowledge. The integration teaching mode in the process of implementing basic teaching competition, classroom teaching is a placement level. Competition is breaking the boundaries of professional, class and grade. After the completion of a classroom teaching content, the organization with the semester all students 
participate in class. For different classes of the students with an opportunity to learn from each other, actively encourage role at the same time can learn their own shortcomings [3].

After the race, and return to the classroom, on the issue of race exposed, the classroom knowledge in again to review and summarize. In this model the process of implementation, teachers with student guidance in the process of interaction and competition, we can timely find the deficiency of classroom teaching and then to adjust and perfect. Additionally, the background of the Internet plus will enhance the performance of the mode, the Fig. 1 shows the keywords of the concept.

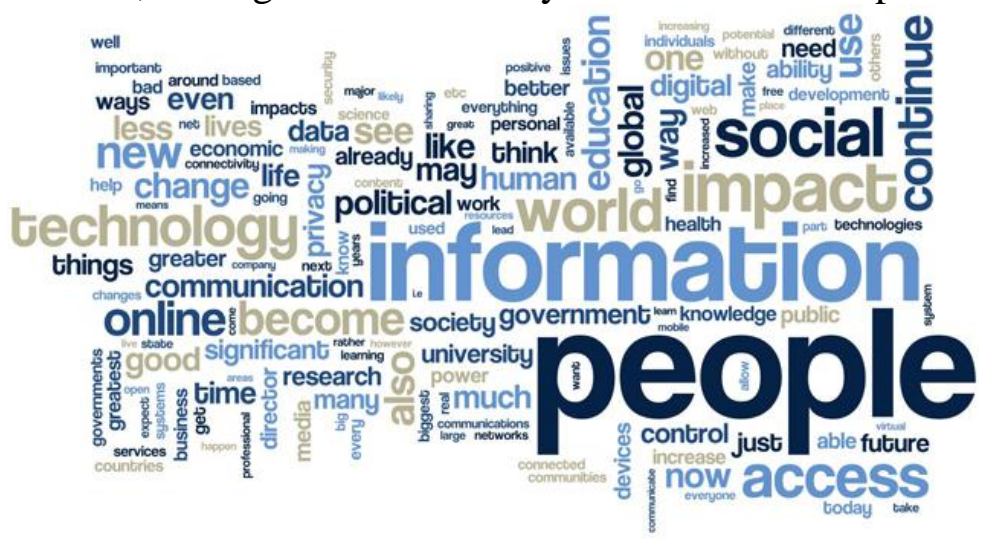

Figure 1. The Keywords of the Internet Plus Background

To enhance the traditional teaching methodology, in this paper, we conduct research on discipline competition based education mode for college students under the Internet plus background. In later sub-sections, we will discuss the perspective in detail.

\section{Our Proposed Methodology}

The Principles of the College Students' Competition. Competition of science and technology and the curriculum of college students have a close relationship with the primary science and technology competition is according to professional curriculum of university students and their extracurricular practice experience formed integrated to solve the problem of one aspect and to carry out academic competition. It can make students to participate in the competition, both into their own professional knowledge, at the same time, improve their practical ability, and in the process of problem solving by constantly thinking and test can also lead to the development of students' independent and innovative thinking. So, the competition for the cultivation of the students' ability of science and technology is very important. The functionality of the competition could be generally summarized as the follows.

- Science and technology competition helps to improve students' interest in learning. Science and technology competition format setting is entertaining, participating students solidarity and the collaboration in the game, racing, got a great sense of accomplishment and happiness in the process, in order to get good grades, they'll understand professional knowledge, efforts to delve into the latest developments in the academic, competition and learning form the good interaction, influence each other, promote each other and eventually improve together.

- Science and technology competition helps to cultivate students' innovative spirit. The various and of all kinds of science and technology competition of current emphasize the discovery and application of innovative thinking, guides the student to the comprehensive use of learned knowledge, solve the specific problems that exist in the real life, in the process, to effectively train the students' creative thinking ability [4-5].

- The competition of science and technology to improve the primary practical ability of student. Competition of science and technology from the traditional test, pay attention to examine the students' comprehensive use of knowledge and creative problem solving skills.

College students of science and technology competition activities is one of the important ways to cultivate high-quality talents, the development of the college students' innovation ability has very big 
effect and influence, to cultivate students' innovative consciousness, innovative thinking and ability. But in the current college students entrepreneurship competition and innovation ability of science and technology, there are many problems in so to improve the college students' science and technology competition management system, set up the college students' science and the technology competition management agencies. College students' science and technology competition project management should be formed to carry out college students' technology competition incentive mechanism to form a good team of students and teachers team, to ensure that the level and quality of college students of the science and technology competition environment.

The Internet Plus Background. Internet industry vigorous development, it is also starting to lead the other industries development, become the source of the other industries development momentum. Massive domestic Internet user means great business opportunities the Internet can change almost all industries. Under this situation, the concept of "Internet $+"$ arises at the historic moment.

The Internet and promote industry amalgamation of new forms and the new business models are created, create more technology, production and service system of multiple formats fusion, caused the adjustment of the industrial development strategy and the transformation. Industry change showed a greater degree than in the past of fusion and penetration, in different industries or different branches in the same industry through mutual penetration as cross gradually form the integration development of new industries or new formats. In the process of new industrial revolution, in order to adapt to the new mode of production, whether internal or industry between will show the new trend of the change of the industrial organization. Based on Internet information technology support system of the allocation of resources, to a great extent, affects the form of industrial organization to make the industry more blurred boundaries. Under this background, we could apply it into the listed aspects.

- Remote research conference features: the meeting need to change the traditional teaching research focused conventional mode, change the site meeting to network video conference that saved the teachers to attend the time delay along the way [6-7].

- Public service platform function: the network teaching is more efficient than the traditional teaching mode, and a wider range, all the teachers to attend inter-school collaborative teaching research, that can through the establishment of the "masters" studio "" personal space" "online evaluation" "mobile phone conference" and so on a variety of ways to come in.

- Synchronous interaction class functions: attend school of collaborative teaching research and related teachers can break the limit of time and space, give play to their respective advantages, use of interactive teaching system to carry out the remote synchronous classroom interaction.

- Along with the advancement of new industrial revolution and the Internet material, basis and dominant factors of industrial convergence conditions shall emerge within a larger industry and play a role to make the industrial convergence, triggering a new industrial revolution.

New industrial revolution further deepened the second and the third industry the development trend of convergence, that fully embedded into industry, services, Internet information technology and the manufacturing technology of disruptive innovation will break the traditional product manufacturing process, manufacturing and services not only vertical integration in the industry chain, industry chain itself will also be recombination fusion. Technical factors, such as the industrial revolution and the Internet will promote the development of industrial convergence and industry integration makes the original discrete industry value chain, some or all of the integration.

The Education Reform and Optimization. Innovation is the source of social progress. Improving the comprehensive quality of college students and training to adapt to the rapid development of the science and technology and to adapt to the economic construction, as cultural construction under the market economy system need high quality innovative talents that is an important task of the current reform of higher school teaching. Teaching as the main ways to cultivate the innovative talents, the teaching quality directly affects growth of innovative talents in universities and colleges. Deepening the reform of higher education teaching the establishment of the innovation education teaching mode, to create good conditions for training innovative talents, becomes the key and core of college teaching reform. Therefore, under the new situation of our country education worker should first as have the 
consciousness of education reform, combining with the experiences and the lessons of the past, in the inheritance and development of education to undertake the mission of history. Secondly, based on the current, with an eye to the future, change blindly following the way of teaching, to develop the more suitable for development of student teaching strategy, for evaluating the current social development trend, based on the analysis of the contemporary college students' mental, to innovate the teaching method reform, strengthen the education to the largest extent and improve the teaching quality.

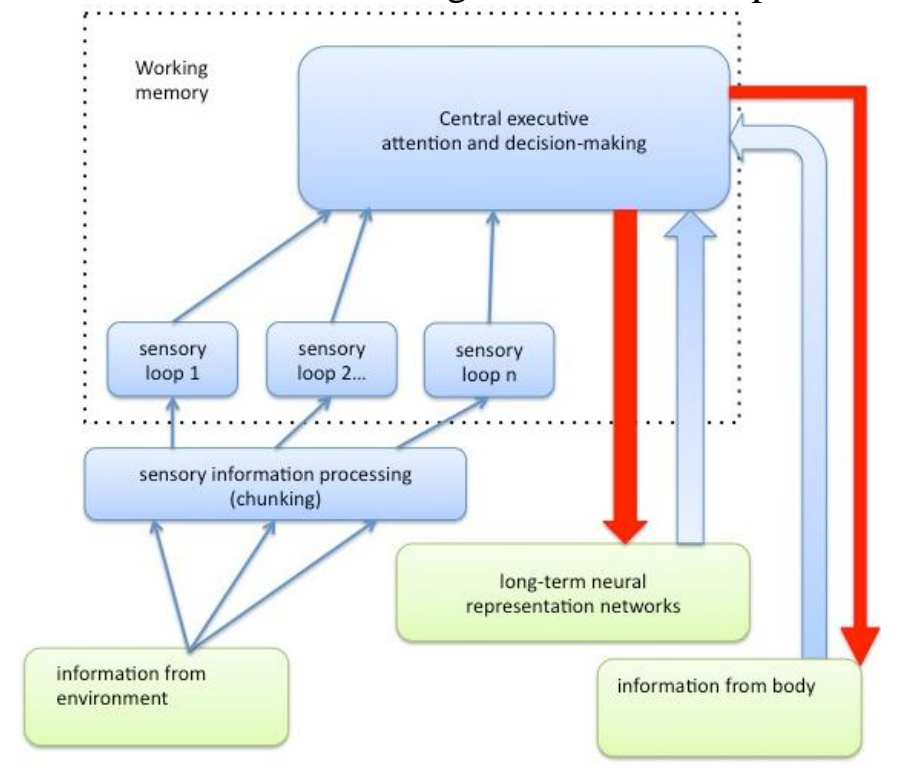

Figure 2. The Flowchart of the Information and Knowledge Capture and Process Procedures

As demonstrated in the Fig. 2, we show the flowchart of the information and knowledge capture and process procedures. Under this guideline, we propose the following potential aspects for the core reform of the education form. (1) Break the class unified system, to carry out flexible credit system, cultivating students' ability of independent access to knowledge and information. College students study in school, on the one hand, in learning professional knowledge, more important is the way to learn knowledge, age in current rapid development, only will be learning to constantly enrich himself, constantly adapt to the needs of the development of practice or adjustment of jobs, therefore, college students have strong ability of self-study is more important than learning knowledge itself, has more significance. (2) Break pure grade assessment system, establish the comprehensive evaluation level, science evaluation the student to the comprehensive understanding of knowledge. To reform current exam system, establish a student to subject development on the basis of the degree of understanding, understanding, and to explore the level of excellent, good, medium and bad judgment system, the students from passive learning to cope with exams for the purpose of to subject knowledge to explore the internal relations for the purpose of active exploration, make students become active consumers of knowledge. (3) For teaching methods innovation, active classroom atmosphere. Strengthen teaching reform, build a new teaching mode, to play their own advantages, highlight the school characteristics, establish and improve the society autonomous systems that meet the needs of teaching management system and operational mechanism, improving the teaching quality, to train high-quality innovative talents to adapt to the new time request [8].

The Competition in Science and Engineering. In science and the engineering students' scientific research ability training system consisting of classroom teaching and the extracurricular practice as the in-class teaching by primary scientific research course counselling, teaching model reform and experimental teaching design of three piece of content that is the integration of professional education and quality education, and form a relatively independent teaching system.

Based on the study of the problems of the study, reform the teaching mode. Due to the practical application characteristics of science and engineering college students' education, the cultivation of the teachers' scientific research basic quality must be infiltrated the course teaching and to cultivate 
students' good scientific research ability. Subject contest is to investigate students' core ability to use discipline theory knowledge to solve problems, actively organize science and engineering students to participate in the professional course contests to apply learned skills, and strengthen its class improve their creation ability. School science and the engineering students are encouraged to participate in the discipline competition, establish the corresponding management organization and system, formation of course contests ", students under the guidance of the teachers to participate in the "normalized, the achievements of the teachers and students, to appropriate reward, so that colleges and universities to form a good academic competition atmosphere. Held as the author's college and to undertake at the provincial level, the field of life sciences and chemical experiment skill competitions for many times, students participate in atmosphere has formed discipline competition, and won the national and the provincial several events breakthrough, the achievement of the students in graduate and apply for the job interview, solid theoretical knowledge and experimental skills is well received by the school and enterprise to raise public awareness of the school personnel training.

\section{Conclusion}

In this paper, we conduct research on current discipline competition based education mode for college students under the Internet plus background. To subject contest as a turning core point of the teaching reform measures have been proposed, and discipline competition gradually deep into the day-to-day teaching and research universities as to improve the students' quality and the ability to pay, one of the important ways to cultivate university students of science and technology universities continuously to explore the competitions, species growing competition, competition has been widely spread. Science and engineering students scientific knowledge and basic research skills through classroom learning to master, and the improvement of scientific research ability must through research activity, deepen their understanding and skillfully use in the process of doing research skills. Under this requirement, we propose the novel education mode to assist optimizing our teaching pattern.

\section{Acknowledgements}

This research was financially supported by the 2015 Research Project of Higher Education Reform in Shaanxi (15BY126) and the 2015 Teaching Reform Research Planning Project of Xijing University (JGGH1511).

\section{References}

[1] P. J. Muñoz-Merino, M. F. Molina, M. Munoz-Organero, C. D. Kloos: Expert Systems with Applications, Vol. 39 (2012) No. 8, p.6932.

[2] N. Chaidarun, S. Tepsuporn, R. Hayes, P. Beling, W. Scherer, S. Grazioli: Proceedings of the Workshop on Principles of Advanced and Distributed Simulation, (2014) No. CD/ROM1, p.3535.

[3] Wilson, Tim: Anatomical Sciences Education (2014).

[4] G. J. Hwang, P. H. Wu, C. C. Chen: Computers \& Education, Vol. 59 (2012) No. 4, p.1246.

[5] W. Guo, D. Feng: Advances in Computer Science and its Applications. Springer Berlin Heidelberg, (2014), p.843.

[6] Y. P. Gao: Experimental Technology and Management, Vol. 4 (2012), p.112.

[7] K. H. Mok: Higher education regionalization in Asia Pacific: Implications for governance, citizenship and university transformation (2012), p.137.

[8] M. Reihlen, M. Markus, M. Mark: Handbook of Research on Entrepreneurship in Professional Services (2012), p.107. 